\title{
Metabolic Syndrome in Offspring of Parents with Metabolic Syndrome: A Meta-Analysis
}

\author{
Laurent Irakoze ${ }^{a, b, d}$ Astère Manirakizac Yunqi Zhang ${ }^{d}$ Juncheng Liu ${ }^{d}$ \\ Jiayu Li ${ }^{d}$ Liliane Nkengurutse $^{e} \quad$ Shuhua Deng $^{f}$ Xiaoqiu Xiao $^{\text {a,d }}$
}

${ }^{a}$ Department of Endocrinology, The First Affiliated Hospital of Chongqing Medical University, Chongqing, PR China; ${ }^{b}$ Kamenge Military Hospital, Ministry of Public Health and Fighting AIDS, Bujumbura, Burundi; ${ }^{c}$ Department of Oncology, The First Affiliated Hospital of Chongqing Medical University, Chongqing, PR China; ${ }^{\mathrm{d}}$ The Chongqing Key Laboratory of Translational Medicine in Major Metabolic Diseases, The First Affiliated Hospital of Chongqing

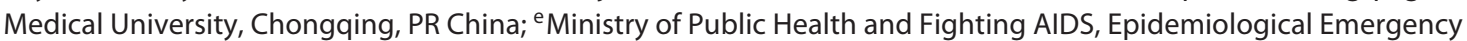

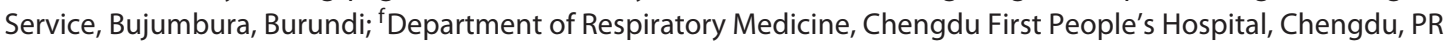
China

\section{Keywords}

Metabolic syndrome $\cdot$ Parent · Offspring · Meta-analysis

\begin{abstract}
Background: The metabolic syndrome (MetS) represents a clustering of risk factors for cardiovascular diseases that includes abdominal obesity, hypertension, dyslipidemia, and insulin resistance. Objectives: The objective of this study was to reassess the parent-offspring association of MetS since the available findings are still controversial. Methods: The Cochrane Library, PubMed, Embase, and Web of Science databases were searched to identify relevant articles. All studies comparing MetS status between the offspring of parents with MetS and offspring of parents without MetS were included in the analysis. Results: A total of 9 studies met the inclusion criteria and they were analyzed. Offspring of at least 1 parent with MetS had a higher risk of MetS (OR 3.88, $95 \% \mathrm{Cl} 2.58-5.83, p<0.001)$. Sons and daughters of fathers
\end{abstract}

karger@karger.com www.karger.com/ofa

Karger $\stackrel{\text { ' }}{5}$

BOPEN ACCESS
(C) 2021 The Author(s)

Published by S. Karger AG, Basel

This article is licensed under the Creative Commons AttributionNonCommercial-NoDerivatives 4.0 International License (CC BY NC-ND) (http://www.karger.com/Services/OpenAccessLicense) Usage and distribution for commercial purposes as well as any distribution of modified material requires written permission. with MetS both had a higher risk of MetS (OR 2.31, 95\% Cl $1.70-3.12, p<0.001$, and OR $1.73,95 \% \mathrm{Cl} 1.37-2.18, p<0.001$, respectively). Sons and daughters of mothers with MetS both had a higher risk of MetS (OR 1.95, 95\% Cl 1.37-2.76, $p=0.0002$, and OR $1.91,95 \% \mathrm{Cl} 1.54-2.35, p<0.001$, respectively). Conclusion: This meta-analysis showed that there is a higher risk of MetS in the offspring of parents with MetS. However, there was no differential association of MetS according to gender and/or age of the offspring.

C 2021 The Author(s)
Published by S. Karger AG, Basel

\section{Introduction}

The metabolic syndrome (MetS) represents a clustering of risk factors for cardiovascular diseases that includes abdominal obesity, hypertension, dyslipidemia, and insulin resistance [1]. It is usually diagnosed when at least 3 of 
the following conditions are present: hypertension, impaired fasting glucose (or impaired glucose tolerance or insulin resistance), central adiposity, systemic inflammation, decreased high-density lipoproteins, and elevated triglycerides [2].

Several definitions for MetS have been developed, which can make comparison between separate studies difficult [1]. Of the definitions of MetS, the most widely used are the National Cholesterol Education Program Adult Treatment Panel III (NCEP ATP III) and the International Diabetes Federation (IDF) [1]. However, a consensus between the American Heart Association/National Heart, Lung and Blood Institute (AHA/NHLBI), and IDF has recently elaborated the AHA/NHLBI definition of MetS. This definition does not include central obesity as a prerequisite [1].

It is important to note that the prevalence of MetS is increasing worldwide [3]. The available evidence indicates that $23 \%$ of the population has this syndrome in Western countries [3]. According to IDF criteria, 1 in 4 adults in the world has MetS [3]. In subjects with MetS, the risk of death, stroke, and heart attacks could be 2-3 times more compared to individuals without this syndrome [3].

The prevalence of MetS is increasing in children and young adults globally [3]. Family is one of the main factors for metabolic risk factors in children. In fact, Mamun et al. [4] showed that excess gestational weight gain does influence offspring obesity over the short and long term, and should therefore be avoided. A meta-analysis by Kawasaki et al. [5] also concluded that exposure to maternal hyperglycemia was associated with offspring obesity and abnormal glucose tolerance. Furthermore, familial factors have been considered as risk factors for MetS, including genetic and environmental factors shared among family members $[3,6,7]$.

Several studies have been recently conducted on the association between parental MetS and offspring MetS [2, 8]. They have shown a parental-offspring association of MetS $[2,8]$. Nevertheless, whether this association depends on the gender of the offspring is still conflicting. In fact, one cross-sectional study found a differential association of MetS according to sex of the offspring, while another cohort study did not $[9,10]$.

To further analyze the parental-offspring association of MetS, we performed a meta-analysis comparing the offspring of parents with MetS and those of parents without MetS. To the best of our knowledge, this is the first meta-analysis on this topic.

Parent-Offspring Association of Metabolic Syndrome

\section{Methods}

Study Selection and Data Extraction

The PubMed, Embase, Web of Science, and Cochrane library databases were searched for relevant papers. The last search was performed on March 14, 2019. To identify all the relevant studies, the search terms were "metabolic syndrome" and "offspring" and "parent" or "parents" or "parental.” Furthermore, reference lists of included studies were searched manually to see whether there are additional studies. The Meta-Analysis of Observational Studies in Epidemiology (MOOSE) guidelines were followed for observational studies [11]. The Preferred Reporting Items for Systematic Reviews and Meta-Analyses (PRISMA) were also followed [12] (online suppl. material; for all online suppl. material, see www. karger.com/doi/10.1159/000513370).

The eligibility criteria were as follows: (1) a study (cohort or cross-sectional study) where there is comparison of MetS status between offspring of parents with MetS and offspring of parents without MetS; (2) the study should be written in English; (3) the study should be published as a full text; (4) the study should have enough data of interest (data presented at least as odds ratios [OR] and confidence intervals [CIs]). The studies which did not fulfill the eligibility criteria were excluded.

To explicitly assess the effects of parental MetS on offspring, the included studies were divided into 6 subgroups: (a) parent-offspring association of MetS when at least 1 parent ( 1 or both) has MetS; (b) parent-offspring association of MetS when both parents have MetS; (c) father-son association of MetS; (d) father-daughter association of MetS; (e) mother-son association of MetS; (f) mother-daughter association of MetS.

\section{Study Quality and Risk of Bias Assessment}

Two authors (L.I. and A.M.) worked independently to search for and assess studies for their methodological quality. The Newcastle-Ottawa quality assessment scale (NOS) for cohort studies was used to assess the methodological quality of the included studies [13]. However, an adapted version of NOS was used to assess the methodological quality of cross-sectional studies [14]. The Newcastle-Ottawa scale assigns a maximum of 4 points for selection ( 5 points for the adapted version of NOS), 2 points for comparability, and 3 points for exposure or outcome $[13,14]$. One or 2 points were awarded for each item present in the selection, comparability, and outcome categories. The highest methodological quality receives a maximum score of 9 stars for cohort studies and 10 stars for cross-sectional studies [15]. Scores $\geq 7$ were considered to indicate high-quality studies, and of scores of 5-6 reflected moderate quality $[13,16]$. Any disagreement in the study was resolved by consensus and, if necessary, a senior staff member was consulted.

\section{Statistical Analysis}

Pooled ORs with 95\% CIs were calculated to assess the combined effect of extracted data (given as ORs and CIs) using StatsDirect version 3.2.8 statistical software. $I^{2}$ and $p$ values were calculated to assess the heterogeneity among studies $\left(I^{2}>50 \%\right.$ and $p<$ 0.1 indicated substantial heterogeneity across studies). The ORs were pooled using only a random effects model to calculate a more conservative result. ORs $<1$ indicated that the offspring of parents with MetS had lower risk of MetS. ORs $>1$ indicated that the offspring of parents with MetS had a higher risk of MetS. 


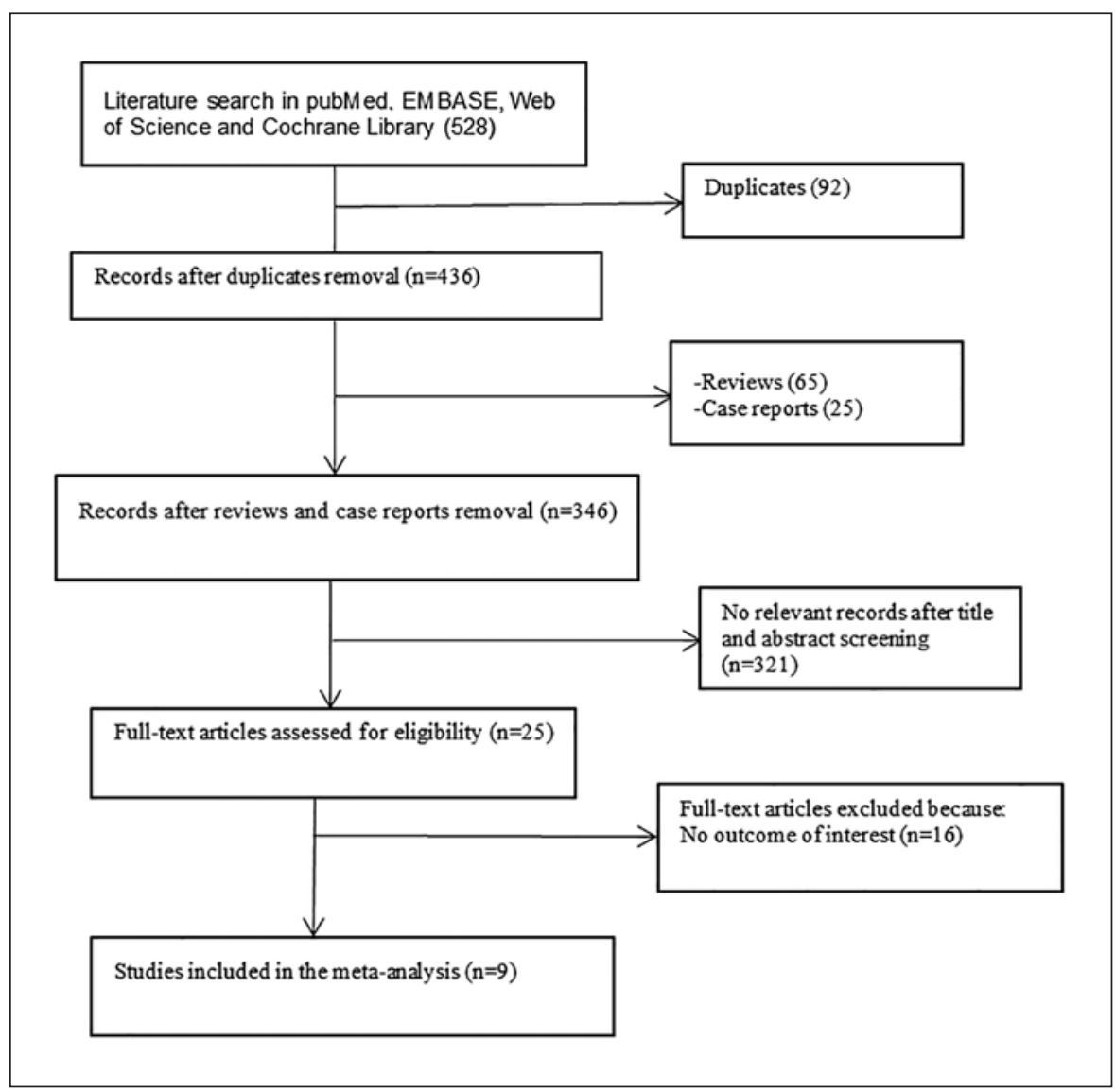

Fig. 1. Flow chart of study selection.

Sensitivity analyses were conducted in case there were no gender differences in offspring inheriting MetS from parents with MetS. They were therefore performed to assess whether the MetS status in offspring of parents with MetS is influenced by the age of the offspring. To assess this, the combined mean of the ages (CMA) of offspring was calculated in 2 groups of studies. The 2 groups consisted of studies with an individual study mean age of offspring $<16$ years, and those studies with an individual study mean age of offspring $>18$ years.

The Egger test for publication bias was not assessed due to the small number of studies in our meta-analysis. The Cochrane metaanalysis guidelines suggest the use of the Egger test for publication bias for analyses with more than 10 studies [17]. $p<0.05$ indicated there was a difference in the outcomes between offspring of parents with MetS and offspring of parents without MetS.

\section{Results}

A total of 528 papers were retrieved from the 4 databases. Of them, 92 were duplicates and 65 were reviews, which were consequently removed. Twenty-five potential studies were ultimately included for full-text view after reviewing the titles and abstracts. With further screening, a total of 9 studies met the inclusion criteria $[9,10,18$ 24]. The flowchart of study selection is shown in Figure 1. The main characteristics of eligible studies are summarized in Table 1 . The publication dates of all the included studies vary between 2006 and 2017.

\section{Study Characteristics}

In 5 studies, the parent-offspring association of MetS was analyzed when at least 1 parent had MetS [18-20, 22, 24]. In 4 studies, this association was analyzed when both parents had MetS [19, 20, 22, 24]. In 4 studies, the fatherdaughter association of MetS was assessed [9, 19, 21, 23]. In 5 studies, the father-son association of MetS was also analyzed $[9,10,19,21,23]$. In 5 studies, the mother-son association for MetS was analyzed [9, 10, 19, 21, 23]. The mother-daughter association of MetS was also assessed in the same studies $[9,10,19,21,23]$. In 2 of the included studies, ORs with adjusted models were preferred [23, 24]. In Lee et al. [20] ORs with a multivariate-adjusted model were chosen.

In 4 studies, the mean age of the offspring was $<16$ years $[18,19,22,24]$. However, in 4 other studies the 
Table 1. Characteristics of the included studies

\begin{tabular}{|c|c|c|c|c|c|c|c|c|}
\hline \multirow[t]{2}{*}{ Reference } & \multirow{2}{*}{$\begin{array}{l}\text { Study design and } \\
\text { region }\end{array}$} & \multirow{2}{*}{$\begin{array}{l}\text { Period of enrollment and/ } \\
\text { or target population }\end{array}$} & \multirow{2}{*}{$\begin{array}{l}\text { MetS } \\
\text { definition } \\
\text { criteria }\end{array}$} & \multirow{2}{*}{$\begin{array}{l}\text { Offspring } \\
\text { mean age, } \\
\text { years }\end{array}$} & \multicolumn{2}{|c|}{ Parent mean age, years } & \multirow{2}{*}{$\begin{array}{l}\text { ORs adjusted for } \\
\text { important } \\
\text { lifestyle and/or } \\
\text { sociodemographic } \\
\text { features }\end{array}$} & \multirow{2}{*}{$\begin{array}{l}\text { Offspring } \\
\text { sample size, } n\end{array}$} \\
\hline & & & & & father & mother & & \\
\hline $\begin{array}{l}\text { Azizi et al. } \\
{[19], 2009}\end{array}$ & $\begin{array}{l}\text { Cross-sectional study } \\
\text { in Tehran, Iran }\end{array}$ & $\begin{array}{l}\text { Offspring of parents with or } \\
\text { without MetS }\end{array}$ & NCEP-ATPIII & 14.4 & 47.1 & 40.2 & Yes & 1,708 \\
\hline $\begin{array}{l}\text { Baxi et al. } \\
{[24], 2015}\end{array}$ & $\begin{array}{l}\text { Cross-sectional study } \\
\text { in Vellore, India }\end{array}$ & $\begin{array}{l}\text { Offspring of parents with or } \\
\text { without MetS }\end{array}$ & IDF & 15.01 & 46.7 & 39.3 & Yes & 304 \\
\hline $\begin{array}{l}\text { Khan et al. } \\
{[23], 2014}\end{array}$ & $\begin{array}{l}\text { Cohort study in } \\
\text { Framingham, USA }\end{array}$ & $\begin{array}{l}\text { Offspring of parents with or } \\
\text { without MetS; 1991-2001 }\end{array}$ & NCEP-ATPIII & 52.9 & 67.8 & 70 & Yes & 1,193 \\
\hline $\begin{array}{l}\text { Klijs et al. } \\
{[9], 2016}\end{array}$ & $\begin{array}{l}\text { Cohort study in the } \\
\text { Netherlands }\end{array}$ & $\begin{array}{l}\text { Offspring of parents with or } \\
\text { without MetS }\end{array}$ & NCEP-ATP III & 37.7 & 65.7 & 63.6 & Yes & 7,239 \\
\hline $\begin{array}{l}\text { Lee et al. } \\
{[10], 2017}\end{array}$ & $\begin{array}{l}\text { Cross-sectional study } \\
\text { in Busan, South Korea }\end{array}$ & $\begin{array}{l}\text { Offspring of parents with or } \\
\text { without MetS; 2010-2013 }\end{array}$ & IDF & 18.6 & 49.6 & 46.4 & Yes & 1,532 \\
\hline $\begin{array}{l}\text { Lee et al. } \\
{[20], 2011}\end{array}$ & $\begin{array}{l}\text { Cross-sectional study } \\
\text { in Seoul, South Korea }\end{array}$ & $\begin{array}{l}\text { Offspring of parents with or } \\
\text { without MetS; April } 6 \text { to } \\
\text { June 18, } 2005\end{array}$ & NCEP-ATPIII & 18.5 & Unclear & Unclear & Yes & 1,342 \\
\hline $\begin{array}{l}\text { Park et al. } \\
{[18], 2006}\end{array}$ & $\begin{array}{l}\text { Cross-sectional study } \\
\text { in Seoul, South Korea }\end{array}$ & $\begin{array}{l}\text { Offspring of parents with or } \\
\text { without MetS; July } 2001 \text { to } \\
\text { February } 2001\end{array}$ & NCEP-ATP III & 13.3 & 43.6 & 40.9 & Yes & 229 \\
\hline $\begin{array}{l}\text { Sabo et al. } \\
{[21], 2012}\end{array}$ & $\begin{array}{l}\text { Longitudinal cohort } \\
\text { study in Virginia, USA }\end{array}$ & $\begin{array}{l}\text { Offspring of parents with or } \\
\text { without MetS }\end{array}$ & NCEP-ATPIII & 28.2 & 59.9 & 59.1 & Unclear & 1,465 \\
\hline $\begin{array}{l}\text { Yoo et al. } \\
{[22], 2012}\end{array}$ & $\begin{array}{l}\text { Cross-sectional study } \\
\text { in Seoul, South Korea }\end{array}$ & $\begin{array}{l}\text { Offspring of parents with or } \\
\text { without MetS; 1998-2008 }\end{array}$ & IDF & 13.85 & 44.3 & 40.9 & Yes & 1,849 \\
\hline
\end{tabular}

mean age of the offspring was more than 18 years $[9,20$, $21,23]$. In 1 study, the mean of age of some of the offspring was more than 18 years, while it was $<16$ years in the remaining offspring [10]. The CMA of offspring was 14.06 years in studies with a mean age of offspring $<16$ years $[10,18,19,22,24]$. The CMA was 34.76 years in studies with a mean age of offspring $>18$ years $[9,10,20$, $21,23]$.

In 3 studies, data on the father-son association for MetS were chosen for sensitivity analyses $[9,10,21]$. Data on the MetS association between both parents and their offspring were chosen in another 2 studies for sensitivity analyses [19, 24]. In Lee et al. [20] data on at least 1 parent-offspring association of MetS was considered for sensitivity analyses. In Khan et al. [23] data on the motherdaughter association of MetS were also selected for sensitivity analyses.

\section{Patient Characteristics}

Baseline characteristics such as gender, age, and level of education were comparable between the offspring of parents with MetS and offspring of parents without MetS. There were no significant differences.

Parent-Offspring Association of Metabolic Syndrome

\section{Publication Bias}

The risk of bias assessment for each study is summarized in Table 2. All included studies were considered to be of high quality.

\section{Outcomes}

Offspring of at least 1 parent with MetS had a higher risk of MetS syndrome than offspring of parents without MetS (OR 3.88, 95\% CI 2.58-5.83, $p<0.001$ ). The heterogeneity was not high $\left(I^{2}=26.2 \%, p=0.24\right.$; Fig. 2$)$.

Offspring of both parents with MetS had a higher risk of MetS when compared with the offspring of parents without MetS (OR 5.06, 95\% CI 2.33-11, $p<0.001$ ). There was a substantial heterogeneity $\left(I^{2}=62.5 \%, p=0.05\right.$; Fig. 3$)$.

Compared with sons of fathers without MetS, sons of fathers with MetS had a higher risk of MetS (OR 2.31, 95\% CI $1.70-3.12, p<0.001)$. The heterogeneity was not high $\left(I^{2}=16 \%, p=0.31\right.$; Fig. 4$)$.

Daughters of fathers with MetS had a higher risk of MetS syndrome when compared with daughters of fathers without MetS (OR 1.73, 95\% CI 1.37-2.18, $p<$ $0.001)$. There was no substantial heterogeneity $\left(I^{2}=0 \%\right.$, $p=0.62$; Fig. 4). 


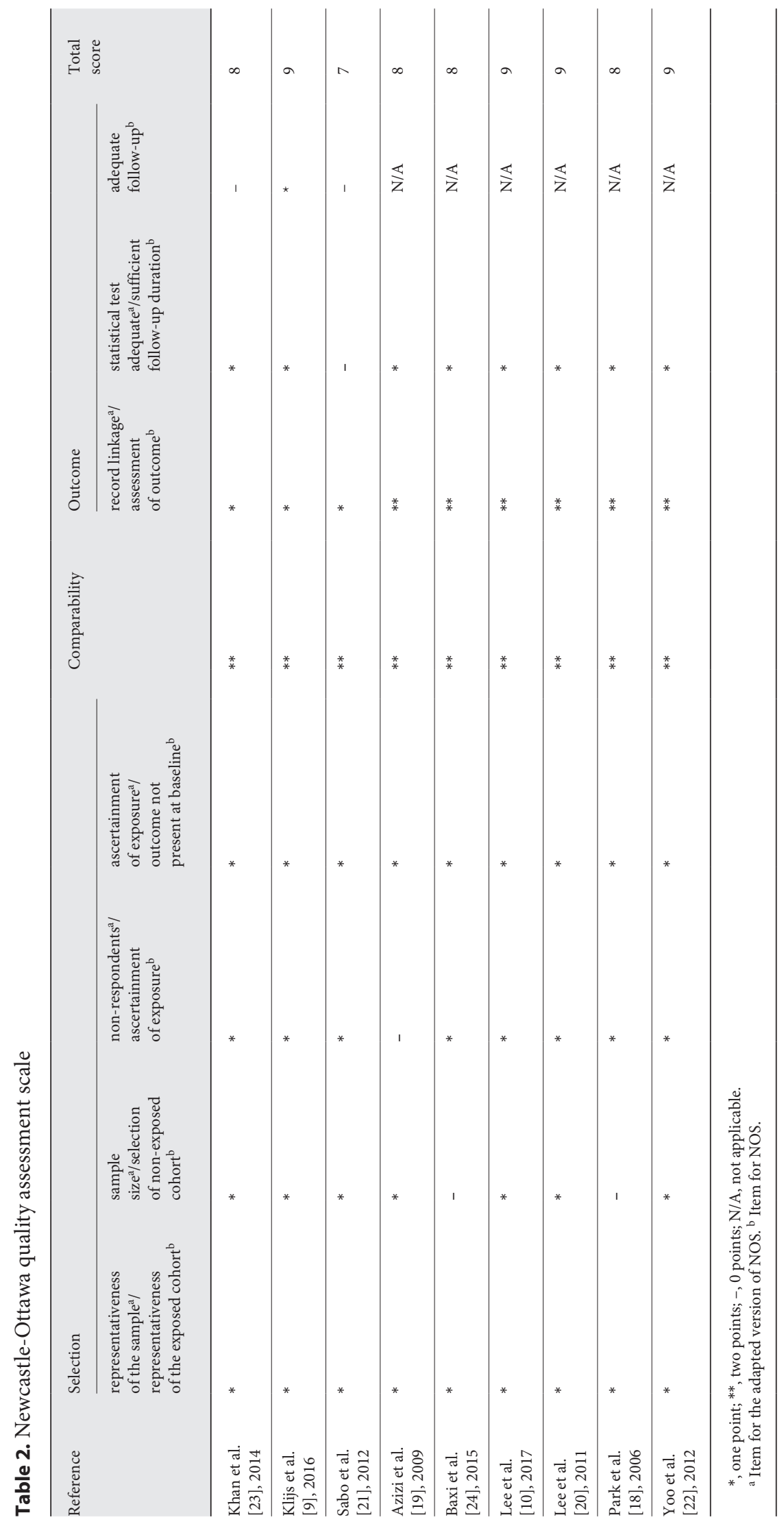




\section{Summary meta-analysis}

\begin{tabular}{|c|c|c|c|c|c|}
\hline Study & Odds Ratio & $\underline{\mathrm{SE}}$ & \multicolumn{2}{|c|}{ Approximate $95 \%$ CI } & \\
\hline 1 & 4,2 & $\overline{0,356672}$ & 2,1 & 8,5 & Yoo 2012 [22] \\
\hline 2 & 8,7 & 0,479808 & 3,4 & 22,3 & Yoo 2012 [22] \\
\hline 3 & 1,83 & 0,458515 & 1,19 & 7,18 & Baxi 2015 [24] \\
\hline 4 & 4,53 & 0,339607 & 2,24 & 8,48 & Azizi 2009 [19] \\
\hline 5 & 4,8 & 0,752364 & 1,1 & 21 & Park 2006 [18] \\
\hline 6 & 2,56 & 0,434254 & 1,09 & 5,98 & Lee M. 2011 [20 \\
\hline
\end{tabular}

$\underline{\text { Stratum }} \underline{\text { Standardized Effect }}$

Stratum
2
3
4
5
6

4,2
8,7
1,8
4,5
4,8
2,5

Standard Error 0,356672 $\begin{array}{lll}0,479808 & 13,283219 & 14,572664 \\ 0,458515 & 14,545556 & 15,621196\end{array}$

$\%$ Weights (fixed, random) $24,038058 \quad 22,28374$ 0,339607 $14,545556 \quad 15,621196$ $26,514569 \quad 23,732422$ $\begin{array}{lll}0,752364 & 5,402337 & 6,847167\end{array}$

Yoo 2012 [22] Yoo 2012 [22] Baxi 2015 [24] Azizi 2009 [19]

4,53 0,434254

16,21626

16,942811

$\underline{\text { Non-combinability of studies }}$

Cochran $Q=6,772855 \quad(d f=5) P=0,2381$

Moment-based estimate of between studies variance $=0,067439$

$I_{2}$ (inconsistency) $=26,2 \%(95 \% C I=0 \%$ to $70,4 \%)$

$\underline{\text { Random effects (DerSimonian-Laird) }}$

Pooled odds ratio $=3,875389(95 \% \mathrm{CI}=2,576535$ to 5,829006$)$

$\mathrm{Z}$ (test Odds Ratio) $=6,504297 \quad \mathrm{P}<0,0001$

Summary meta-analysis plot [random effects]

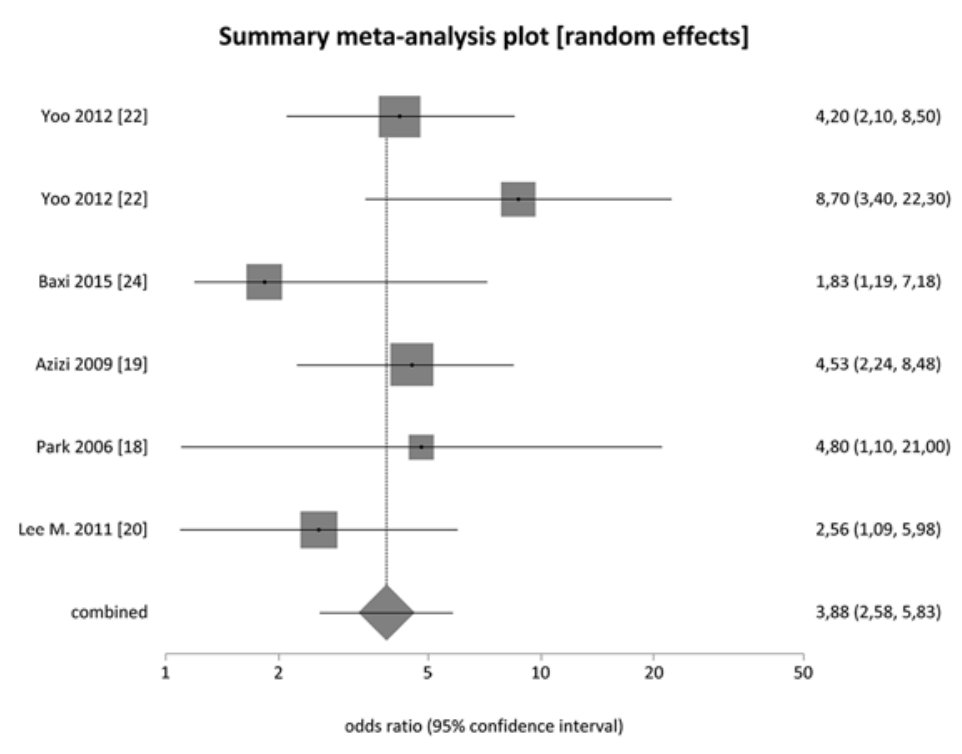
offspring association of MetS (at least 1 parent had MetS).

Sons of mothers with MetS had a higher risk of MetS than sons of mothers without MetS (OR 1.95, 95\% CI $1.37-2.76, p=0.0002)$. The heterogeneity was not high $\left(I^{2}=43.4 \%, p=0.13\right.$; Fig. 5).

Daughters of mothers with MetS had a higher risk of MetS when compared with daughters of mothers without MetS (OR 1.91, 95\% CI 1.54-2.35, $p<0.001$ ). There was no substantial heterogeneity $\left(I^{2}=0 \%, p=0.78\right.$; Fig. 5$)$.
Sensitivity analyses showed that the offspring of parents with MetS with a CMA of 14.06 years and those with a CMA of 34.76 years both had higher risk of MetS (OR 4.35, 95\% CI 2.82-6.69, $p<0.001$, and OR 2.29, 95\% CI 1.9-2.77, $p<$ 0.001 , respectively). There was no substantial heterogeneity (offspring with a CMA of 14.06 years, $p=0.28$; offspring with a CMA of 34.76 years, $p=0.47$; Fig. 6,7 ). 
Fig. 3. Summary meta-analysis of parentoffspring association of MetS (both parents had MetS).

\section{$\underline{\text { Summary meta-analysis }}$}

\begin{tabular}{|c|c|c|c|c|c|}
\hline Study & Odds Ratio & $\underline{\mathrm{SE}}$ & \multicolumn{2}{|c|}{ Approximate $95 \% \mathrm{Cl}$} & \\
\hline 1 & 8,7 & $\overline{0,479808}$ & 3,4 & 22,3 & Yoo 2012 [22] \\
\hline 2 & 15,58 & 0,822531 & 3,11 & 78,17 & Lee M. 2011 [20] \\
\hline 3 & 4,53 & 0,329339 & 2,42 & 8,8 & Azizi 2009 [19] \\
\hline 4 & 1,83 & 0,458515 & 1,19 & 7,18 & Baxi 2015 [24] \\
\hline
\end{tabular}

Stratum Standardized Effect Standard Error \% Weights (fixed, random)

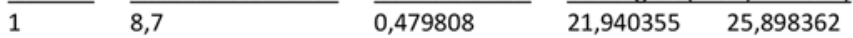
$\begin{array}{lllll}2 & 15,58 & 0,822531 & 7,465744 & 14,921371\end{array}$ $\begin{array}{lllll}3 & 4,53 & 0,329339 & 46,568499 & 32,400044\end{array}$ $\begin{array}{lllll}4 & 1,83 & 0,458515 & 24,025402 & 26,780222\end{array}$ Yoo 2012 [22] Lee M. 2011 [20] Azizi 2009 [19] Baxi 2015 [24]

$\underline{\text { Non-combinability of studies }}$

Cochran $Q=8,007013 \quad(d f=3) P=0,0459$

Moment-based estimate of between studies variance $=0,376512$

$\mathrm{I}_{2}$ (inconsistency) $=62,5 \%(95 \% \mathrm{Cl}=0 \%$ to $85,3 \%)$

$\underline{\text { Random effects (DerSimonian-Laird) }}$

Pooled odds ratio $=5,059745(95 \% \mathrm{Cl}=2,326553$ to 11,003841$)$

$Z$ (test Odds Ratio) $=4,090108 \quad P<0,0001$

\section{Summary meta-analysis plot [random effects]}

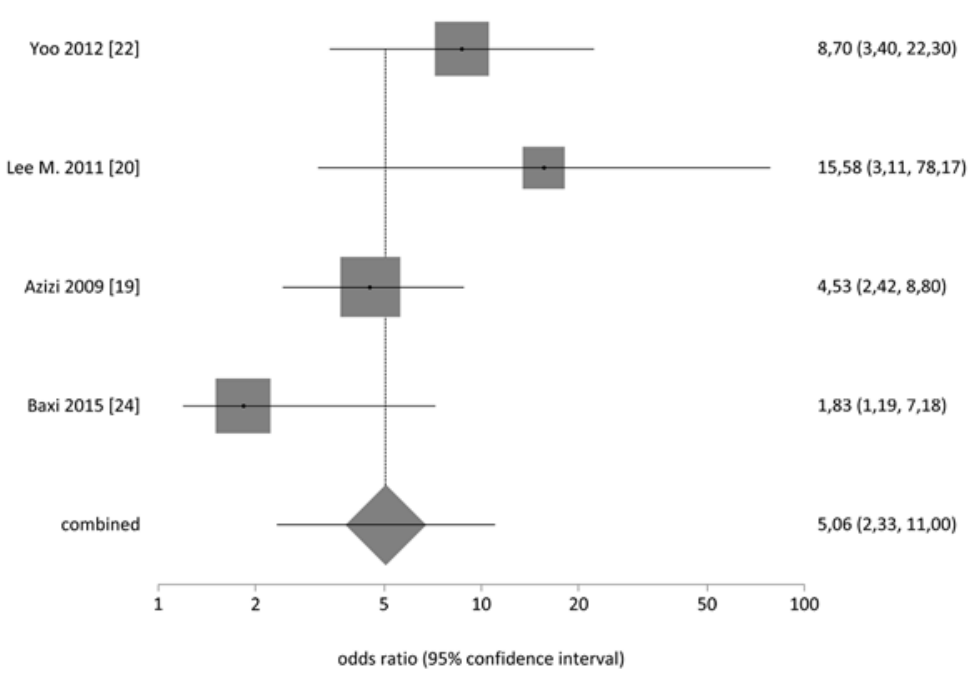

\section{Discussion}

The results of this meta-analysis show that offspring of parents with MetS syndrome have a higher risk of MetS (Fig. 2, 3). They also show that MetS in parents is associated with MetS in offspring, irrespective of the gender and/or age of the offspring (Fig. 4-7).
Many studies have been conducted on the parent-offspring association of MetS [9, 10, 19, 21, 23, 25]. They have shown an association of MetS between parents and offspring $[9,18,22,26]$. However, it remains controversial whether there is a differential association of MetS according to gender or age of the offspring $[9,10,21,23]$. In fact, Sabo et al. [21] concluded that MetS in parents is significantly associated with MetS in adult male offspring. 
Fig. 4. Summary meta-analysis of fatherson and/or father-daughter association of MetS.
Summary meta-analysis for father-daughter association of MetS

\begin{tabular}{llllll}
$\underline{\text { Study }}$ & & Odds Ratio & & $\underline{\text { SE }}$ & \multicolumn{3}{c}{ Approximate 95\% Cl } & \\
1 & 2,21 & 0,436369 & 0,94 & 5,2 & Azizi 2009 [19] \\
2 & 1,1 & 0,55334 & 0,4 & 3,5 & Sabo 2012 [21] \\
3 & 1,8 & 0,131779 & 1,39 & 2,33 & Klijs 2016 [9] \\
4 & 1,21 & 0,424872 & 0,59 & 3,12 & Khan 2014 [23]
\end{tabular}

Stratum Standardized Effect $\underline{\text { Standard Error } \% \text { Weights (fixed, random) }}$

$\begin{array}{lllllll}1 & 2,21 & 0,436369 & & 7,330358 & 7,330358 & \\ 2 & 1,1 & 0,55334 & & 4,558773 & 4,558773 & \text { Sabo 2012 [21] } \\ 3 & 1,8 & 0,131779 & & 80,378418 & 80,378418 & \text { Klijs 2016 [9] } \\ 4 & 1,21 & 0,424872 & & 7,732451 & 7,732451 & \text { Khan 2014 [23] }\end{array}$

$\underline{\text { Non-combinability of studies }}$

Cochran $Q=1,782988 \quad(d f=3) P=0,6186$

Moment-based estimate of between studies variance $=0$

$\mathrm{I}_{2}$ (inconsistency) $=0 \%(95 \% \mathrm{Cl}=0 \%$ to $67,9 \%)$

$\underline{\text { Random effects (DerSimonian-Laird) }}$

Pooled odds ratio $=1,732677(95 \% \mathrm{Cl}=1,374523$ to 2,184152$)$

$Z$ (test Odds Ratio) $=4,652472 \quad P<0,0001$

Summary meta-analysis plot [random effects]

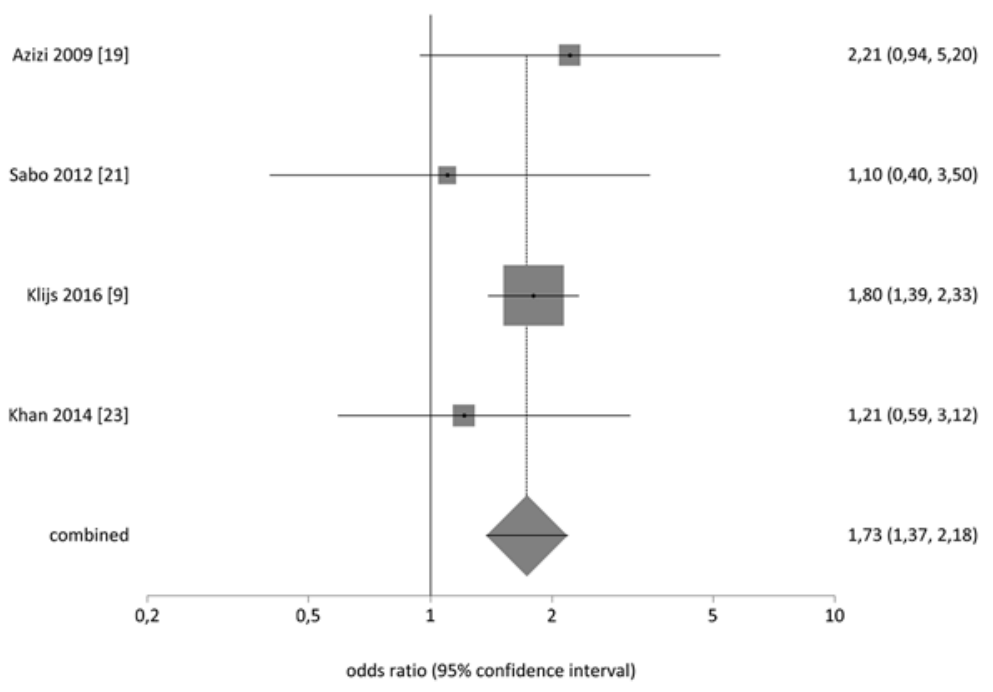

(Figure continued on next page.)
Another study by Khan et al. [23] demonstrated that a mother's MetS was strongly related with her daughter's MetS, but the association was inconsistent with her son's MetS. The same authors did not find any association between a father's MetS and his offspring's MetS [23]. Lee et al. [10] found that there were differential associations of MetS according to offspring gender and age group and the parent's gender. In fact, the associations of MetS were significantly stronger in young adults versus adolescents and in male offspring versus female offspring [10]. However, this meta-analysis showed that there is an association of MetS between parents and offspring, irrespective of gender and/or age of the offspring (Fig. 4-7).

A biased design and/or smaller sample size in Sabo et al. [21], Khan et al. [23], and/or Lee et al. [10] might explain why there was a differential association of MetS sta- 


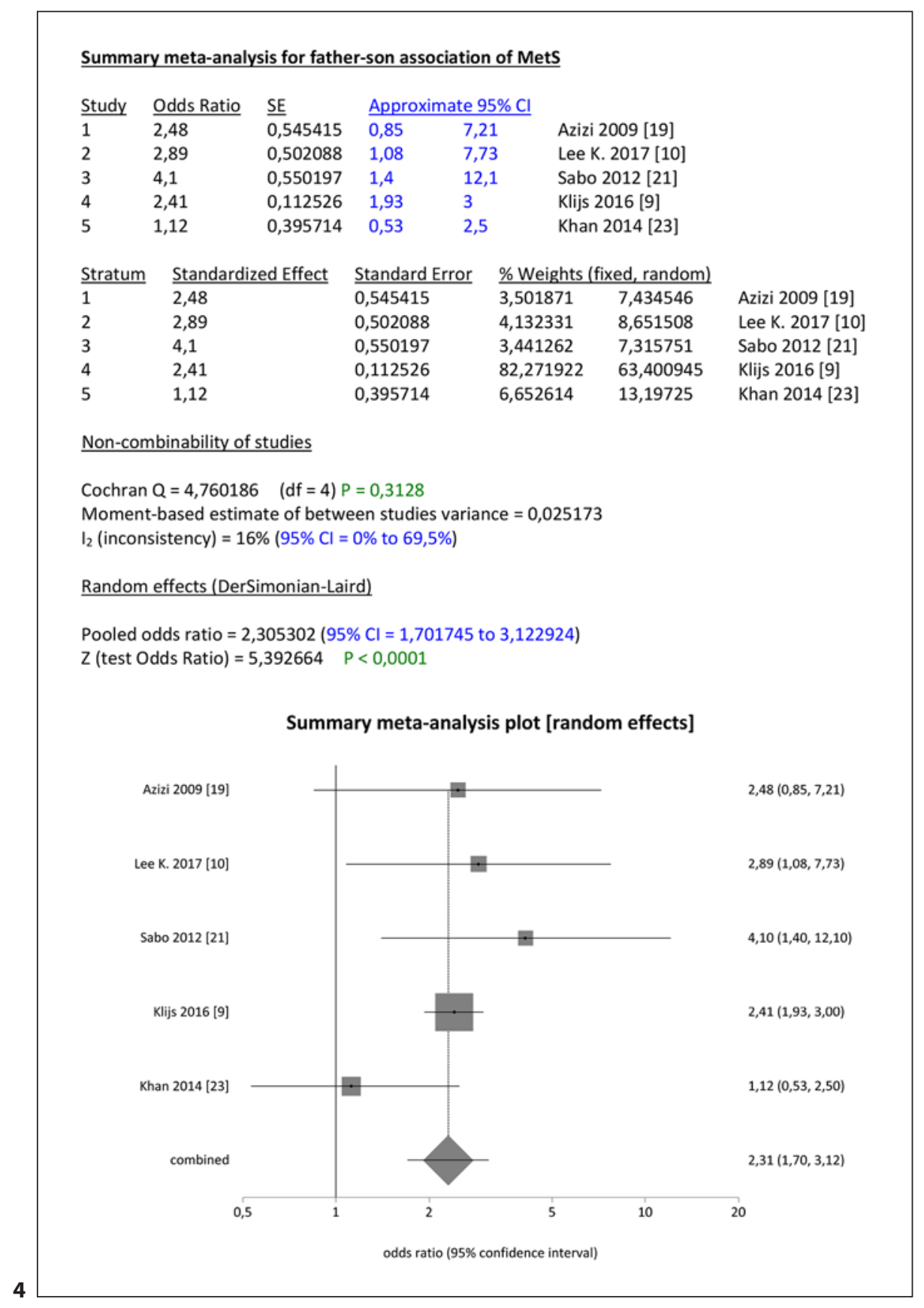

tus in the offspring according to sex and/or age. This is supported in part by a study by Klijs et al. [9] with a sufficiently larger sample size. In this study, the authors concluded that a high risk of MetS is transmitted from fathers and mothers to sons and daughters, irrespective of the gender of the offspring. They also suggested that this transmission is irrespective of the socioeconomic position and health behaviors of the offspring. Furthermore, an accumulating body of evidence suggests that maternal obesity and excessive weight gain during pregnancy is associated with offspring obesity over the short and long term $[4,27]$. As obesity is at the core of MetS [28], this may also explain why MetS in parents is also associated with offspring MetS over the short and long term. However, this needs further verification. 
Summary meta-analysis for mother-son association of MetS

\begin{tabular}{|c|c|c|c|c|c|}
\hline Study & $\underline{\text { Odds Ratio }}$ & $\underline{\mathrm{SE}}$ & \multicolumn{2}{|c|}{ Approximate $95 \% \mathrm{CI}$} & \\
\hline & 2,6 & $\overline{0,519032}$ & 0,94 & 7,19 & Lee K. 2017 [10] \\
\hline & 3,94 & 0,437518 & 1,67 & 9,28 & Azizi 2009 [19] \\
\hline & 2,5 & 0,410578 & 1,1 & 5,5 & Sabo 2012 [21] \\
\hline & 1,82 & 0,118346 & 1,44 & 2,29 & Klijs 2016 [9] \\
\hline & 1,17 & 0.260046 & 0,7 & 1,94 & Khan 2014 \\
\hline
\end{tabular}

\begin{tabular}{|c|c|c|c|c|c|}
\hline Stratum & $\underline{\text { Standardized Effect }}$ & $\underline{\text { Standard Error }}$ & \multicolumn{2}{|c|}{$\%$ Weights (fixed, random) } & \\
\hline 1 & 2,6 & 0,519032 & 3,673297 & 9,499587 & Lee K. 2017 [10] \\
\hline 2 & 3,94 & 0,437518 & 5,169546 & 12,395717 & Azizi 2009 [19] \\
\hline 3 & 2,5 & 0,410578 & 5,87018 & 13,61167 & Sabo 2012 [21] \\
\hline 4 & 1,82 & 0,118346 & 70,653681 & 40,468176 & Klijs 2016 [9] \\
\hline 5 & 1,17 & 0,260046 & 14,633297 & 24,02485 & Khan 2014 [23] \\
\hline
\end{tabular}

Non-combinability of studies

Cochran $\mathrm{Q}=7,068111 \quad(\mathrm{df}=4) \mathrm{P}=0,1323$

Moment-based estimate of between studies variance $=0,064334$

$\mathrm{I}_{2}$ (inconsistency) $=43,4 \%(95 \% \mathrm{CI}=0 \%$ to $77,9 \%)$

$\underline{\text { Random effects (DerSimonian-Laird) }}$

Pooled odds ratio $=1,945498(95 \% \mathrm{CI}=1,372372$ to 2,75797$)$

$\mathrm{Z}$ (test Odds Ratio) $=3,737757 \quad \mathrm{P}=0,0002$

Fig. 5. Summary meta-analysis of motherson and/or mother-daughter association of MetS.
Summary meta-analysis plot [random effects]

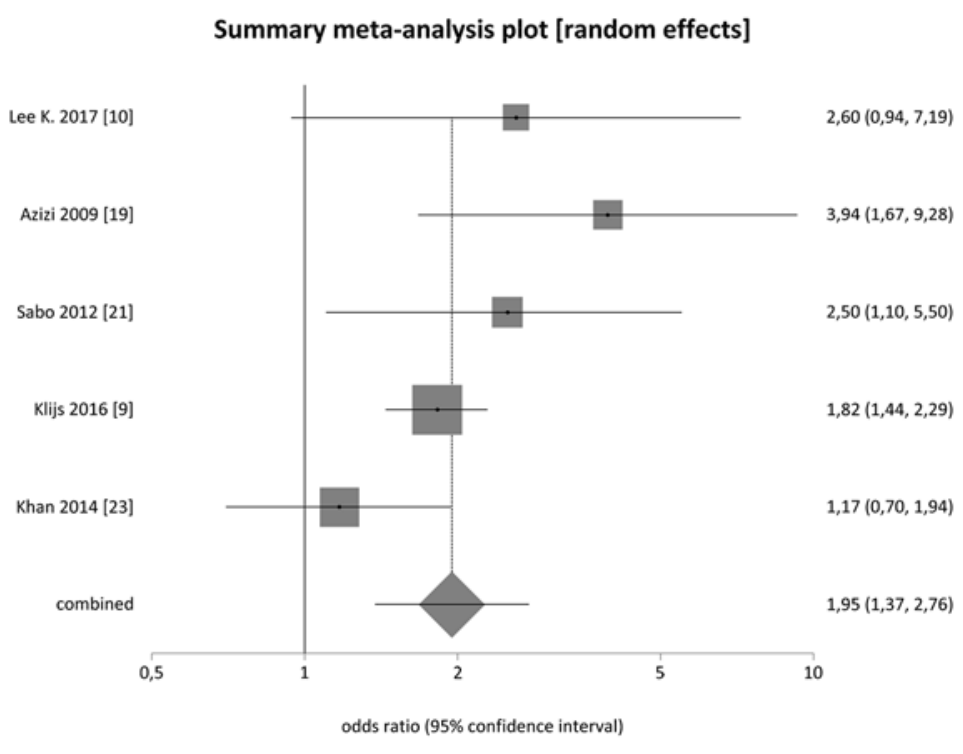

(Figure continued on next page.)
There are several hypothesized mechanisms that explain the pathophysiology of MetS $[29,30]$. The most widely accepted of these is insulin resistance with fatty acid flux [30]. Other important mechanisms including low-grade chronic inflammation and oxidative stress have also been mentioned [30]. The strong parent-offspring association of MetS may be due to hereditary or environmental factors. In fact, it is widely recognized that genetic and environmental factors both contribute to the development of MetS [22,31-33]. Twin and family studies have revealed substantial familial aggregation of MetS risk factors [34]. Bellia et al. [26] showed high prevalence rates for the MetS and its related traits in an isolated and small Caucasian population. Obesity, at the core of MetS, is itself highly heritable through shared genetic and environmental factors [34]. If a parent is obese, his or her 


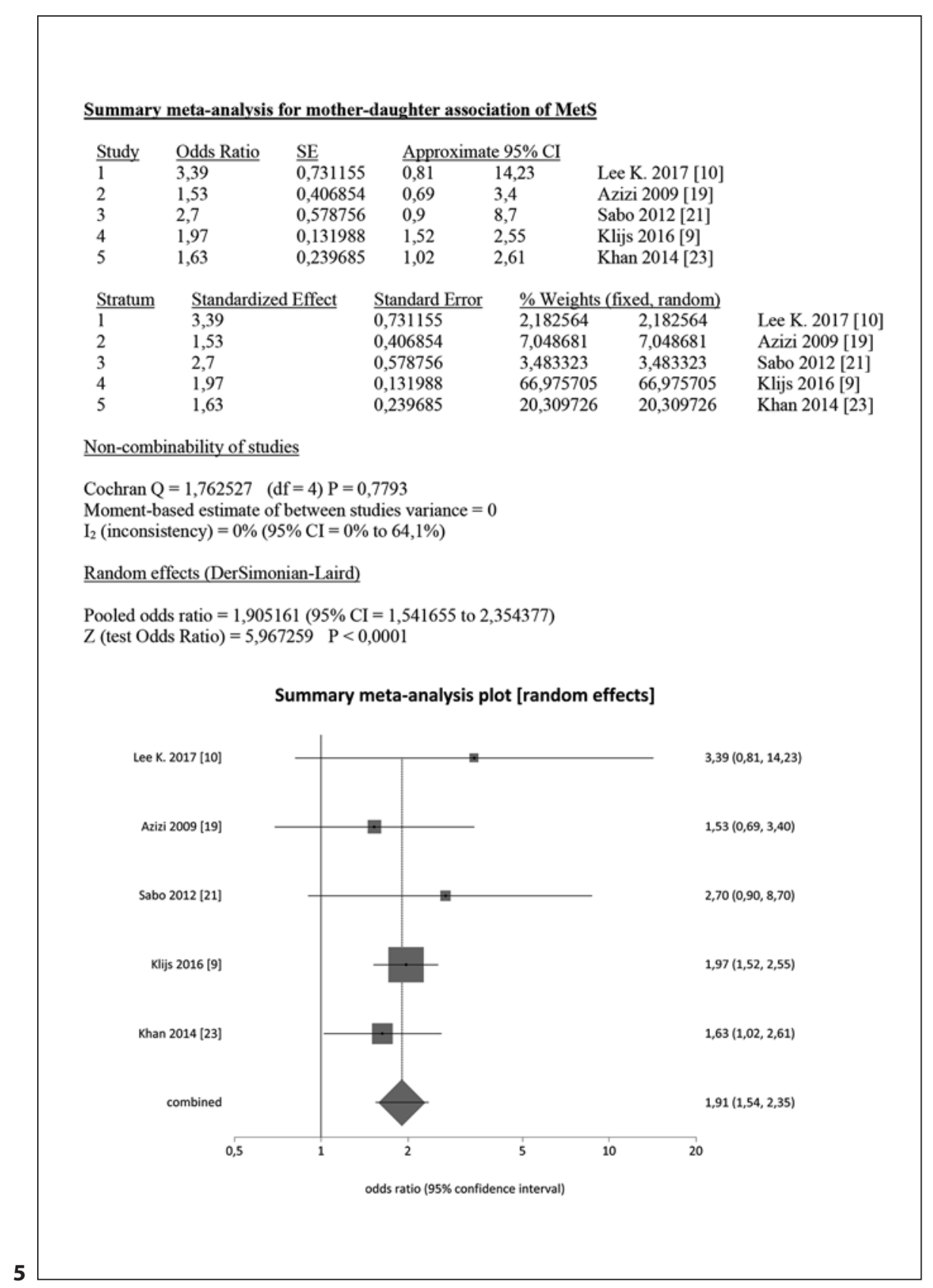

child is twice as likely to be obese [34]. Conversely, more than half of children with obesity have at least 1 parent with obesity [34].

In animal models, Li et al. [35] demonstrated that paternal hyperglycemia induces transgenerational inheritance of susceptibility to hepatic steatosis in rats involving altered methylation on the Ppar $\alpha$ promoter. The same authors concluded that their findings might have implica- tions for the understanding of father-offspring interactions with the potential to account for MetS. In addition, it has been shown that poor maternal and paternal periconceptional nutrition can increase the risk of MetS in offspring through epigenetic imprinting [2].

Patients with MetS may have an increased risk of disease, approximately 2 -fold for cardiovascular disease and 5 -fold or more for type 2 diabetes mellitus [28]. In addi- 
Fig. 6. Summary meta-analysis for MetS status in offspring of parents with MetS when offspring CMA is 14.06 years.

Summary meta-analysis for MetS status in offspring of parents with MetS when offspring CMA is 14.06 years

\begin{tabular}{|c|c|c|c|c|c|c|c|c|}
\hline$\underline{\text { Study }}$ & $\underline{\text { Odds Ratio }}$ & $\underline{\mathrm{SE}}$ & \multicolumn{3}{|c|}{ Approximate $95 \% \mathrm{Cl}$} & \multirow{2}{*}{\multicolumn{2}{|c|}{ Lee K. 2017 [10] }} & \\
\hline 1 & 11,7 & 1,245237 & 1,02 & \multicolumn{2}{|c|}{134,43} & & & \\
\hline 2 & 4,2 & 0,356672 & 2,1 & \multicolumn{2}{|c|}{8,5} & & \\
\hline 3 & 8,7 & 0,482085 & 3,4 & \multicolumn{2}{|l|}{22,5} & \multicolumn{2}{|c|}{ Yoo 2012 [22] } & \\
\hline 4 & 4,8 & 0,752364 & 1,1 & \multicolumn{2}{|l|}{21} & \multicolumn{2}{|c|}{ Park 2006 [18] } & \\
\hline 5 & 4,53 & 0,329339 & 2,42 & \multicolumn{2}{|l|}{8,8} & \multicolumn{2}{|c|}{ Park 2006 [18] } & \\
\hline 6 & 1,83 & 0,458515 & 1,19 & \multicolumn{2}{|l|}{7,18} & \multicolumn{2}{|c|}{ Baxi 2015 [24] } & \\
\hline$\underline{\text { Stratum }}$ & \multicolumn{2}{|c|}{$\underline{\text { Standardized Effect }}$} & \multicolumn{2}{|c|}{$\underline{\text { Standard Error }}$} & \multicolumn{3}{|c|}{ \% Weights (fixed, random) } & \\
\hline 1 & \multicolumn{2}{|c|}{11,7} & \multicolumn{2}{|c|}{1,245237} & \multicolumn{3}{|c|}{$2,258762 \quad 3,008531$} & Lee K. 2017 [10] \\
\hline 2 & \multicolumn{2}{|l|}{4,2} & \multicolumn{2}{|c|}{0,356672} & \multicolumn{2}{|c|}{27,531927} & 25,915351 & Yoo 2012 [22] \\
\hline 3 & \multicolumn{2}{|l|}{8,7} & \multicolumn{2}{|c|}{0,482085} & \multicolumn{2}{|c|}{15,070475} & 16,583895 & Yoo 2012 [22] \\
\hline 4 & \multicolumn{2}{|l|}{4,8} & \multicolumn{2}{|c|}{0,752364} & \multicolumn{2}{|c|}{6,187553} & 7,741953 & Park 2006 [18] \\
\hline 5 & \multicolumn{2}{|l|}{4,53} & \multicolumn{2}{|c|}{0,329339} & \multicolumn{2}{|c|}{32,291569} & 28,804475 & Azizi 2009 [19] \\
\hline 6 & \multicolumn{2}{|l|}{1,83} & \multicolumn{2}{|c|}{0,458515} & \multicolumn{2}{|c|}{16,659715} & 17,945795 & Baxi 2015 [24] \\
\hline
\end{tabular}
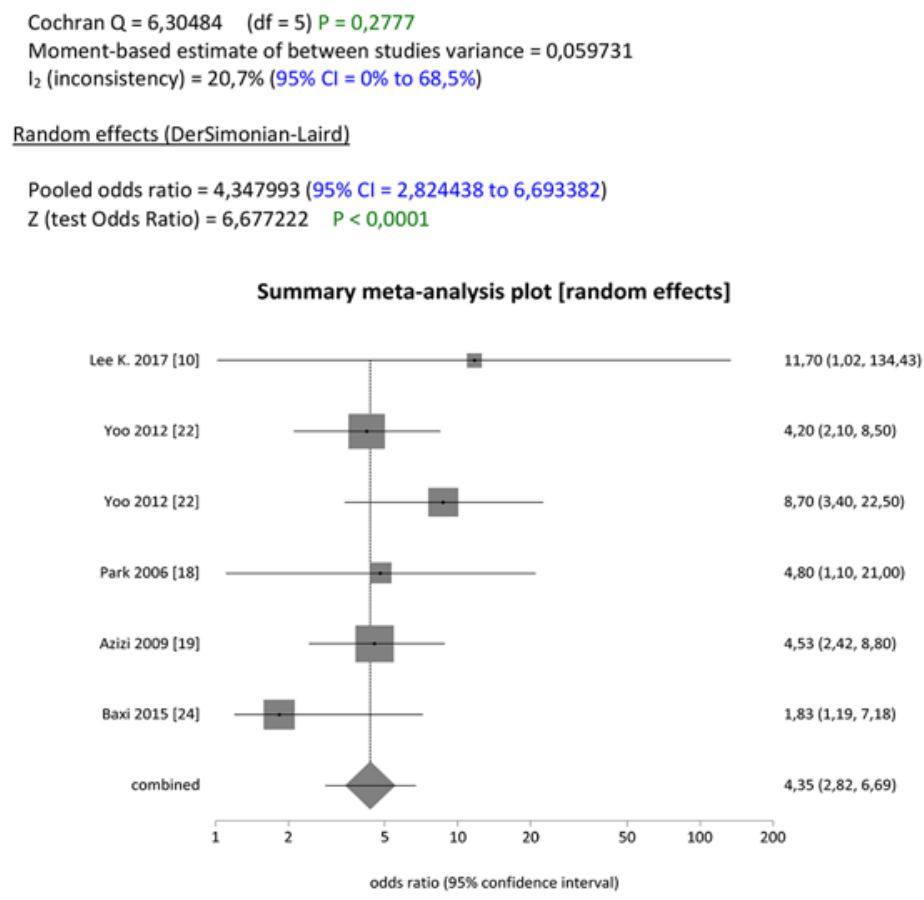

tion, they are prone to some comorbidities, including non-alcoholic fatty liver disease, polycystic ovary syndrome, obstructive sleep apnea, and mental health disorders [34]. Therefore, treatments and/or lifestyle changes could be of great importance to reverse or delay MetS sequelae.

This study presents some limitations. First, there was a lack of enough studies. Second, most of those included were cross-sectional studies. Third, although most of the studies included used IDF or NCEP-ATP III criteria to define MetS, there are still variations in defining MetS, especially in young adolescents [34]. Fourth, whether parents and offspring lived under the same

Parent-Offspring Association of Metabolic Syndrome roof and were on the same diet is unclear. Lastly, there was an absence of studies in languages other than English, as only English published articles were considered. Therefore, further well-designed studies in humans and/or animal models should be conducted to verify these findings.

\section{Conclusion}

This meta-analysis showed that there is a higher risk of MetS in the offspring of parents with MetS. However, gender and/or age differences were not found to be asso- 
Fig. 7. Summary meta-analysis for MetS status in offspring of parents with MetS when offspring CMA is 34.76 years.
Summary meta-analysis for MetS status in offspring of parents with MetS when offspring CMA is 34.76 years

\begin{tabular}{|c|c|c|c|c|c|}
\hline Study & Odds Ratio & $\underline{\mathrm{SE}}$ & \multicolumn{2}{|c|}{ Approximate $95 \% \mathrm{Cl}$} & \\
\hline 1 & 2,56 & 0,434254 & 1,09 & 5,98 & Lee M. 2011 [20] \\
\hline 2 & 2,41 & 0,112526 & 1,93 & 3 & Klijs 2016 [9] \\
\hline 3 & 4,1 & 0,550197 & 1,4 & 12,1 & Sabo 2012 [21] \\
\hline 4 & 1,63 & 0,239685 & 1,02 & 2,61 & Khan 2014 [23] \\
\hline 5 & 1,84 & 0,606701 & 0,56 & 6,04 & Lee K. 2017 [10] \\
\hline
\end{tabular}

$\underline{\text { Stratum }}$ Standardized Effect $\quad \underline{\text { Standard Error } \% \text { Weights (fixed, random) }}$ $\begin{array}{lllll}1 & 2,56 & 0,434254 & 4,923481 & 4,923481\end{array}$

$\begin{array}{lllll}2 & 2,41 & 0,112526 & 73,325726 & 73,325726\end{array}$

$\begin{array}{lllll}3 & 4,1 & 0,550197 & 3,067061 & 3,067061\end{array}$

$4 \quad 1,63 \quad 0,239685 \quad 16,161353 \quad 16,161353$

$\begin{array}{lllll}5 & 1,84 & 0,606701 & 2,522379 & 2,522379\end{array}$

Lee M. 2011 [20]

Klijs 2016 [9]

Sabo 2012 [21]

Khan 2014 [23]

Lee K. 2017 [10]

Non-combinability of studies

Cochran $Q=3,534439 \quad(d f=4) P=0,4727$

Moment-based estimate of between studies variance $=0$

$\mathrm{I}_{2}$ (inconsistency) $=0 \%(95 \% \mathrm{Cl}=0 \%$ to $64,1 \%)$

\section{$\underline{\text { Random effects (DerSimonian-Laird) }}$}

Pooled odds ratio $=2,290778(95 \% \mathrm{Cl}=1,896551$ to 2,766951$)$

$\mathrm{Z}$ (test Odds Ratio) $=8,602369 \quad \mathrm{P}<0,0001$

Summary meta-analysis plot [random effects]

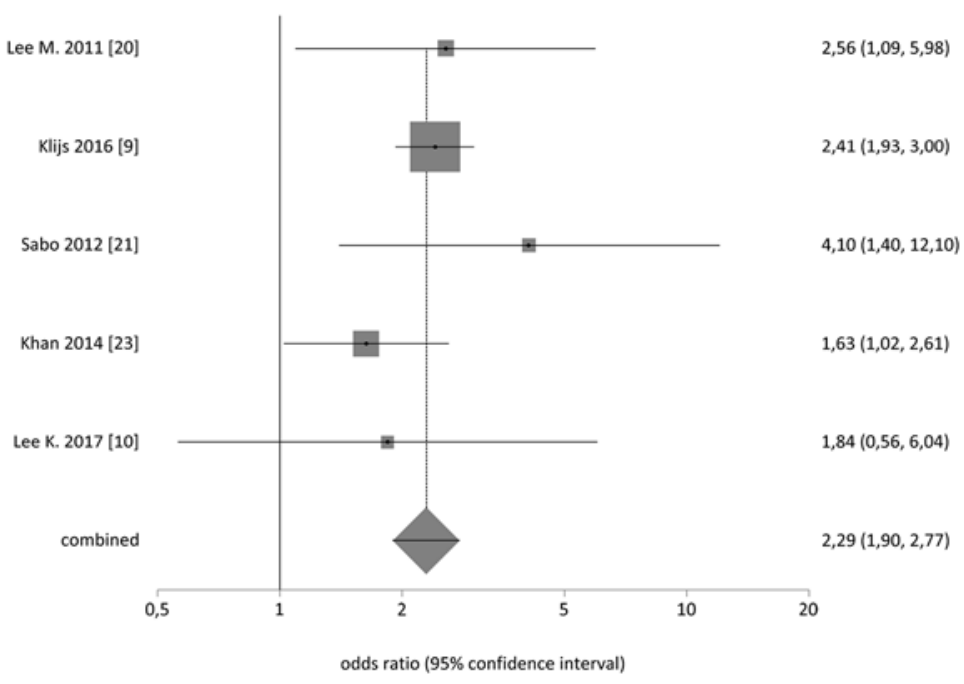

ciated with offspring inheriting MetS from their parents. Further studies are still needed to verify these findings.

\section{Acknowledgements}

We thank John Belly for his advice.

\section{Statement of Ethics}

This report is exempt from Ethical Committee approval since it is based on previously conducted studies and does not involve any new studies of human or animal subjects performed by any of the authors. 


\section{Conflict of Interest Statement}

All authors declare that they have no conflicts of interest.

\section{Funding Sources}

The study was supported by Natural Science Foundation of China grants (81871222 and 81570763), and the Fundamental Science and Advanced Technology Research of Chongqing (major project, CSTC2015jcyjB0146 to X.X.).

\section{Author Contributions}

L.I. contributed to the study design, researched the data, contributed to the discussion, and wrote and edited the manuscript. A.M. extracted data and participated in the statistical analyses. Y.Z., Ju.L., Ji.L., L.N., and S.D. contributed to the discussion and reviewed the manuscript. X.X. is guarantor of this work and has full access to all the data in the study. He takes responsibility for the integrity of the data and the accuracy of the data analysis.

\section{References}

1 Martin-Iguacel R, Negredo E, Peck R, FriisMøller N. Hypertension is a key feature of the metabolic syndrome in subjects aging with HIV. Curr Hypertens Rep. 2016 Jun;18(6):46.

2 Dunford AR, Sangster JM. Maternal and paternal periconceptional nutrition as an indicator of offspring metabolic syndrome risk in later life through epigenetic imprinting: a systematic review. Diabetes Metab Syndr. 2017 Dec;11 Suppl 2:S655-62.

3 Naseri P, Khodakarim S, Guity K, Daneshpour MS. Familial aggregation and linkage analysis with covariates for metabolic syndrome risk factors. Gene. 2018 Jun;659:11822.

4 Mamun AA, Mannan M, Doi SA. Gestational weight gain in relation to offspring obesity over the life course: a systematic review and bias-adjusted meta-analysis. Obes Rev. 2014 Apr;15(4):338-47.

5 Kawasaki M, Arata N, Miyazaki C, Mori R, Kikuchi T, Ogawa Y, et al. Obesity and abnormal glucose tolerance in offspring of diabetic mothers: A systematic review and meta-analysis. PLoS One. 2018 Jan;13(1):e0190676.

6 Barbosa JP, Basso L, Bartholomeu T, Rezende JA, Oliveira JA, Prista A, et al. Familial aggregation and heritability of markers of metabolic risk, physical activity, and physical fitness in nuclear families from Muzambinho (Minas Gerais, Brazil). Arch Endocrinol Metab. 2019 May-Jun;63(3):215-21.

7 Nolan PB, Carrick-Ranson G, Stinear JW, Reading SA, Dalleck LC. Parent's cardiorespiratory fitness, body mass, and chronic disease status is associated with metabolic syndrome in young adults: a preliminary study. Int J Environ Res Public Health. 2019 May; 16(10):E1768.

8 Miranda-Lora AL, Vilchis-Gil J, Molina-Díaz $\mathrm{M}$, Flores-Huerta $\mathrm{S}$, Klünder-Klünder $\mathrm{M}$. Heritability, parental transmission and environment correlation of pediatric-onset type 2 diabetes mellitus and metabolic syndromerelated traits. Diabetes Res Clin Pract. 2017 Apr;126:151-9.
9 Klijs B, Angelini V, Mierau JO, Smidt N. The role of life-course socioeconomic and lifestyle factors in the intergenerational transmission of the metabolic syndrome: results from the LifeLines Cohort Study. Int J Epidemiol. 2016 Aug;45(4):1236-46.

10 Lee K. Metabolic syndrome in Korean adolescents and young adult offspring and their parents. Asia Pac J Clin Nutr. 2017;26(4):713-8.

11 Koopman AD, Beulens JW, Voerman E, Rauh SP, van der Heijden AA, McDonald TJ, et al. The association between GAD65 antibody levels and incident Type 2 Diabetes Mellitus in an adult population: A meta-analysis. Metabolism. 2019 Jun;95:1-7.

12 Moher D, Liberati A, Tetzlaff J, Altman DG; PRISMA Group. Preferred reporting items for systematic reviews and meta-analyses: the PRISMA statement. PLoS Med. 2009 Jul; 6(7):e1000097.

13 Xing D, Xu Y, Liu Q, Ke Y, Wang B, Li Z, et al. Osteoarthritis and all-cause mortality in worldwide populations: grading the evidence from a meta-analysis. Sci Rep. 2016 Apr;6(1): 24393.

14 Modesti PA, Reboldi G, Cappuccio FP, Agyemang C, Remuzzi G, Rapi S, et al. Panethnic Differences in Blood Pressure in Europe: A Systematic Review and Meta-Analysis. PLoS One. 2016 Jan;11(1):e0147601.

15 Al-Zalabani AH, Noor Elahi I, Katib A, Alamri AG, Halawani A, Alsindi NM, et al. Association between soft drinks consumption and asthma: a systematic review and meta-analysis. BMJ Open. 2019 Oct;9(10):e029046.

16 Song Y, Xu Y, Liang Z, Yang Y, Liu X. Lower body mass index and higher height are correlated with increased varicocele risk. Andrologia. 2019 Nov;51(10):e13391.

17 Laurent I, Tang S, Astère M, Wang KR, Deng S, Xiao L, et al. Liquid L-thyroxine versus tablet L-thyroxine in patients on L- thyroxine replacement or suppressive therapy: a meta-analysis. Endocrine. 2018 Jul;61(1): $28-35$.

18 Park HS, Park JY, Cho SI. Familial aggregation of the metabolic syndrome in Korean families with adolescents. Atherosclerosis. 2006 May;186(1):215-21.
19 Azizi F, Farahani ZK, Ghanbarian A, Sheikholeslami F, Mirmiran P, Momenan AA, et al. Familial aggregation of the metabolic syndrome: Tehran Lipid and Glucose Study. Ann Nutr Metab. 2009;54(3):189-96.

20 Lee MH, Kim HC, Thomas GN, Ahn SV, Hur NW, Choi DP, et al. Familial concordance of metabolic syndrome in Korean populationKorean National Health and Nutrition Examination Survey 2005. Diabetes Res Clin Pract. 2011 Sep;93(3):430-6.

21 Sabo RT, Lu Z, Deng X, Ren C, Daniels S, Arslanian S, et al. Parental and offspring associations of the metabolic syndrome in the Fels Longitudinal Study. Am J Clin Nutr. 2012 Sep;96(3):461-6.

22 Yoo EG, Park SS, Oh SW, Nam GB, Park MJ. Strong parent-offspring association of metabolic syndrome in Korean families. Diabetes Care. 2012 Feb;35(2):293-5.

23 Khan RJ, Rotimi CN, Gebreab SY, Crespo PR, $\mathrm{Xu} \mathrm{RH}$, Davis SK. Parent-offspring association of metabolic syndrome in the Framingham Heart Study. Diabetol Metab Syndr. 2014 Dec;6(1):140.

24 Baxi R, Vasan SK, Hansdak S, Samuel P, Jeyaseelan V, Geethanjali FS, et al. Parental determinants of metabolic syndrome among adolescent Asian Indians: A cross-sectional analysis of parent-offspring trios. J Diabetes. 2016 Jul;8(4):494-501.

25 Liese AD, Mayer-Davis EJ, Tyroler HA, Davis CE, Keil U, Schmidt MI, et al. Familial components of the multiple metabolic syndrome: the ARIC study. Diabetologia. 1997 Aug; 40(8):963-70.

26 Bellia A, Giardina E, Lauro D, Tesauro M, Di Fede G, Cusumano G, et al. "The Linosa Study": epidemiological and heritability data of the metabolic syndrome in a Caucasian genetic isolate. Nutr Metab Cardiovasc Dis. 2009 Sep;19(7):455-61.

27 Gaillard R. Maternal obesity during pregnancy and cardiovascular development and disease in the offspring. Eur J Epidemiol. 2015 Nov;30(11):1141-52.

28 Samson SL, Garber AJ. Metabolic syndrome. Endocrinol Metab Clin North Am. 2014 Mar; 43(1):1-23. 
29 Rochlani Y, Pothineni NV, Kovelamudi S, Mehta JL. Metabolic syndrome: pathophysiology, management, and modulation by natural compounds. Ther Adv Cardiovasc Dis. 2017 Aug;11(8):215-25.

30 McCracken E, Monaghan M, Sreenivasan S. Pathophysiology of the metabolic syndrome. Clin Dermatol. 2018 Jan - Feb;36(1):14-20.

31 Marciniak A, Patro-Małysza J, Kimber-Trojnar Ż, Marciniak B, Oleszczuk J, LeszczyńskaGorzelak B. Fetal programming of the metabolic syndrome. Taiwan J Obstet Gynecol. 2017 Apr;56(2):133-8.
32 Belva F, Bonduelle M, Provyn S, Painter RC, Tournaye H, Roelants M, et al. Metabolic syndrome and its components in young adults conceived by ICSI. Int J Endocrinol. 2018 May;2018:8170518.

33 Huang G, Cherkerzian S, Loucks EB, Buka SL, Handa RJ, Lasley BL, et al. Sex Differences in the Prenatal Programming of Adult Metabolic Syndrome by Maternal Androgens. J Clin Endocrinol Metab. 2018 Nov;103(11):394553.
34 Magge SN, Goodman E, Armstrong SC; Committee on nutrition; section on endocrinology; section on obesity. The Metabolic Syndrome in Children and Adolescents: Shifting the Focus to Cardiometabolic Risk Factor Clustering. Pediatrics. 2017 Aug; 140(2):e20171603.

35 Li X, Shi X, Hou Y, Cao X, Gong L, Wang H, et al. Paternal hyperglycemia induces transgenerational inheritance of susceptibility to hepatic steatosis in rats involving altered methylation on Ppara promoter. Biochim Biophys Acta Mol Basis Dis. 2019 Jan;1865(1): $147-60$. 